\title{
An unusual presentation of acute myocardial infarction in physiotherapy direct access: findings from a case report
}

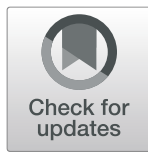

\author{
Lorenzo Storari $^{1}$ (D), Valerio Barbari ${ }^{1}$ (D), Fabrizio Brindisino ${ }^{2}$ (D), Marco Testa ${ }^{1}$ (D) and Maselli Filippo ${ }^{1 *}$ (D)
}

\begin{abstract}
Background: Shoulder pain (SP) may originate from both musculoskeletal and visceral conditions. Physiotherapists (PT) may encounter patients with life-threatening pathologies that mimic musculoskeletal pain such as Acute Myocardial Infarction (AMI). A trained PT should be able to distinguish between signs and symptoms of musculoskeletal or visceral origin aimed at performing proper medical referral.

Case presentation: A 46-y-old male with acute SP lasting from a week was diagnosed with right painful musculoskeletal shoulder syndrome, in two successive examinations by the emergency department physicians. However, after having experienced a shift of the pain on the left side, the patient presented to a PT. The PT recognized the signs and symptoms of visceral pain and referred him to the general practitioner, which identified a cardiac disease. The final diagnosis was acute myocardial infarction.

Conclusion: This case report highlights the importance of a thorough patient screening examination, especially for patients treated in an outpatient setting, which allow distinguishing between signs and symptoms of musculoskeletal from visceral diseases.
\end{abstract}

Keywords: Anterior wall myocardial infarction, Differential diagnosis, Referral and consultation, Shoulder pain, Physiotherapy

\section{Background}

Shoulder pain (SP) is one of the most common musculoskeletal (MSK) disorders in the general population with a prevalence ranging from 7 to $27 \%$ among adults younger than 70 years-old [1]. SP is the third most common MSK disease after lower back and neck pain, furthermore, it is also one of the most prevalent complaints in outpatient clinic [1, 2], and in emergency department (ED) $[3,4]$. Most of the patients consulting healthcare professionals for SP (in primary and secondary care) have been diagnosed with subacromial impingement

\footnotetext{
* Correspondence: masellifilippo76@gmail.com

'Department of Neurosciences, Rehabilitation, Ophthalmology, Genetic and Maternal Infantile Sciences (DINOGMI), University of Genova - Campus of Savona, Savona, Italy

Full list of author information is available at the end of the article
}

syndrome, rotator cuff tendinopathy and adhesive capsulitis $[1,5,6]$. However, in addition to the musculoskeletal or mechanic origin of pain, healthcare professionals must be alert that visceral [7], or serious potential lifethreatening illnesses may refer pain to the shoulder, such as cardiovascular disorders [7-9]. In fact, patients with cardiovascular pathologies may present crushing, substernal chest pain, abdominal pain, jaw pain, neck pain, diaphoresis, dyspnea, fatigue and arm or shoulder referred pain as main signs and symptoms $[8,9]$, with some differences given by sex [8].

Among cardiovascular pathologies, high rates of both incidence and prevalence are represented by acute myocardial infarction (AMI ) [10, 11, 11], which most common sites of pain are chest, upper limb and abdomen $[12,13]$. Unfortunately, these possible referred pain

\section{$\triangle B M C$}

(c) The Author(s). 2021 Open Access This article is licensed under a Creative Commons Attribution 4.0 International License, which permits use, sharing, adaptation, distribution and reproduction in any medium or format, as long as you give appropriate credit to the original author(s) and the source, provide a link to the Creative Commons licence, and indicate if changes were made. The images or other third party material in this article are included in the article's Creative Commons licence, unless indicated otherwise in a credit line to the material. If material is not included in the article's Creative Commons licence and your intended use is not permitted by statutory regulation or exceeds the permitted use, you will need to obtain permission directly from the copyright holder. To view a copy of this licence, visit http://creativecommons.org/licenses/by/4.0/ The Creative Commons Public Domain Dedication waiver (http://creativecommons.org/publicdomain/zero/1.0/) applies to the data made available in this article, unless otherwise stated in a credit line to the data. 
locations could lead to misleading diagnosis even in ED context [14]. Therefore, healthcare professionals, including physiotherapist (PT), should evaluate each possible underlying cause during the evaluation of patients referring SP $[9,15,16]$. Currently, there is sparse literature regarding cases of differential diagnosis made by PT in patients with musculoskeletal diseases [17-19], especially in case of cardiogenic referred pain [20]. Moreover, it is not available at present any reports related to an acute life-threatening condition such as AMI. We report the case of a patient presented to an outpatient physiotherapy clinic with SP that quickly shifted from the right to the left shoulder, which has been properly recognized as visceral related pain by the PT, and finally referred to an appropriate medical management.

\section{Case presentation}

A 46-y-old tiler male presented to the ED complaining of right SP during the previous week due to increased workload (13-14 $\mathrm{h}$ per day laying bulky tiles, instead of his usual $8 \mathrm{~h}$ of daily work). His vitals parameters were pulse oxygen saturation level of $99 \%$, blood pressure (BP) of $130 / 90 \mathrm{mmHg}$, respiratory rate (RR) of $16 \mathrm{rpm}$, and heart rate (HR) of $72 \mathrm{bpm}$. Cardiopulmonary and neurological examinations were unremarkable. The patient denied family history for cardiovascular disease, any medication intake in the previous $48 \mathrm{~h}$, and declared being smoker since 20 years. Physical examination documented worsening of pain on palpation of the acromial and scapular region stated with numeric pain rating (NPRS) scale at $8 / 10$, and there were no other abnormalities in other physical examinations (Fig. 1). The pain was described as dull and intense, lasting from a week, with a subtle onset. He was diagnosed by the ED physician with right painful musculoskeletal (MSK) shoulder syndrome and treated with an intramuscular injection of diclofenac $75 \mathrm{mg} / \mathrm{mL}$ and ketorolac $30 \mathrm{mg} / \mathrm{mL}$, with no relief. Accordingly, to reduce the pain and calm down the patient, the physician prescribed an infusion of saline solution $(100 \mathrm{~mL}$ and $250 \mathrm{~mL})$ and ranitidine hydrochloride $50 \mathrm{mg} / 5 \mathrm{~mL}$ and a diazepam dose $10 \mathrm{mg} / 2 \mathrm{~mL}$, which led to a sensible improvement of the pain.

Upon discharge, the patient was advised to take eperisone hydrochloride $100 \mathrm{mg}$ twice and ibuprofen $600 \mathrm{mg}$ twice a day for 5 days, rest from work for 1 week and a prescription of antalgic electrotherapies.
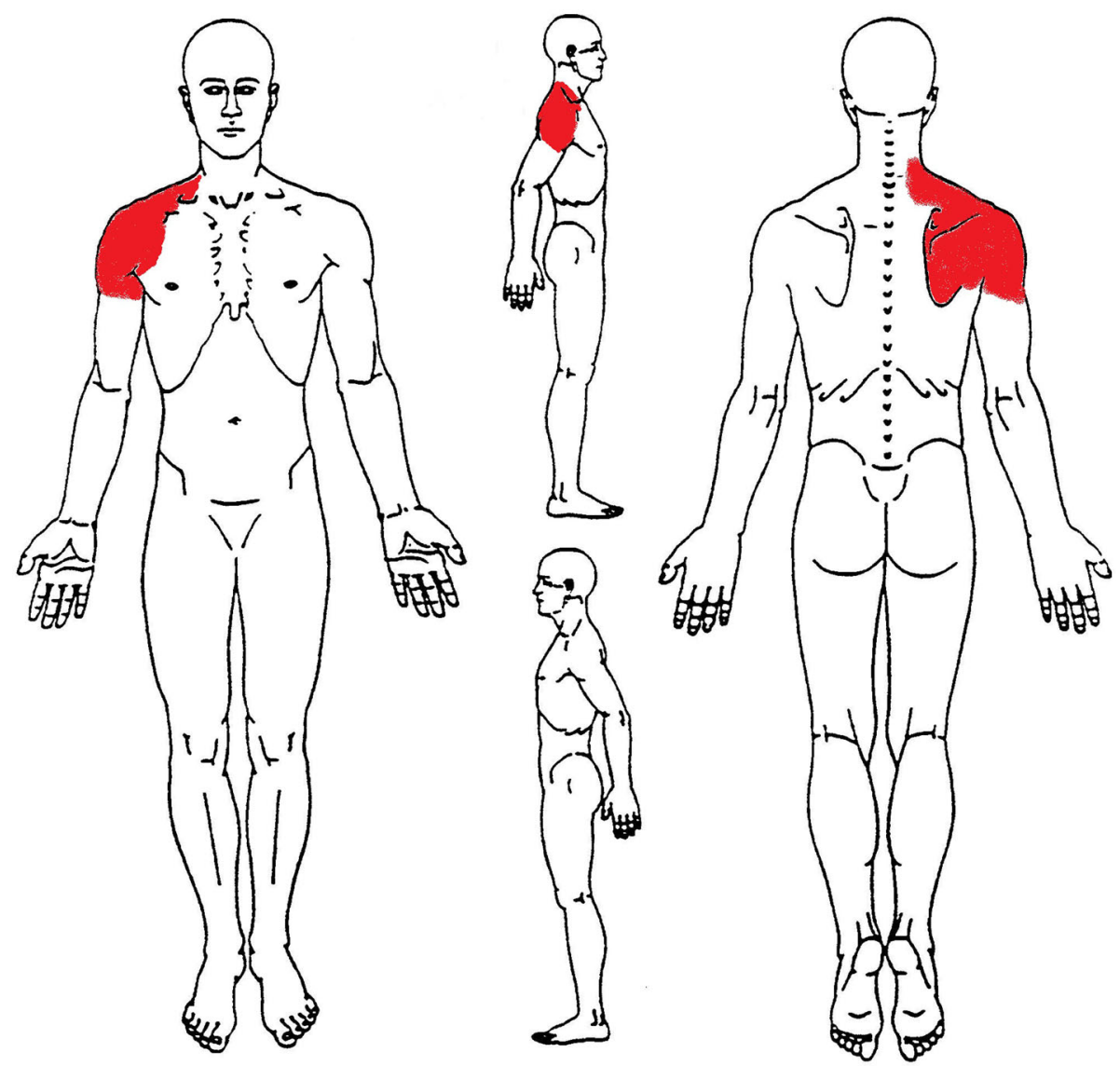

Fig. 1 Body chart. Symptoms at 1st ED visit. In red NPRS 8/10 at rest 
The patient decided to seek his PT to have another evaluation. On examination, he arrived at the clinic holding his upper limb in an antalgic posture, with his arm adducted and internally rotated using a foulard knotted behind the neck. His past medical history included frequent recurrent right shoulder dislocations in the childhood, which had been resolved with muscle strengthening, and chronic gastritis (treated with antacid drugs when needed). The patient denied any other past or current traumas or diseases. He also denied general constitutional symptoms, any unexplained recent weight loss or gain, or bowel or bladder symptoms. He reported smoking 30 cigarettes per day, a body mass index of 27 , $6 \mathrm{~kg} / \mathrm{m}^{2}$ and denied any congenital or family history of heart diseases. Disability scored 56.57 on the QuickDASH scale [21]. The physical assessment of the shoulder documented pain on the palpations of the upper trapezius, supraspinatus, infraspinatus, anterior and posterior deltoid muscles with reproduction of symptoms, NPRS $=8 / 10$. Hence, vital parameters were not evaluated $[13,15,22,23]$.

Passive range of motion (ROM) of the shoulder was evaluated. Elevation and abduction were both limited to 70 degrees with an empty end-feel [24]. Internal rotation had a painful capsular end-feel and full ROM, whereas external rotation and extension had full ROM and painfree capsular end-feel. Due to the functional limitation, the abduction and adduction movements on the horizontal plane were performed at 70 degrees of elevation. The abduction had a capsular end-feel while adduction had a tissue approximation end-feel, both pain-free. Active ROM movements of the right shoulder were requested: elevation and abduction were both limited to 70 degrees due to sharp pain in the whole deltoid region, while extension was normal. Due to the pain, external rotation had been performed between $0^{\circ}$ and $70^{\circ}$ degrees of elevation and were normal, as well as internal rotation, abduction and adduction on the horizontal plane. Manual isometric muscle tests were accomplished for the rotator cuff muscles, deltoid, trapezius, biceps brachialis, triceps and pectoralis major and minor, in accordance with muscle testing usual practice [25], reporting strength comparable to that of the left shoulder (4/5 level on the medical research council scale [MRC] )[26]. To complete the physical examination, active and passive movements of the cervical spine were evaluated [25, 27-29] and were within normal ranges, also upper limb neurodynamic tests were found normal $[30,31]$. Due to high irritability, absence of trauma or relevant risk factors for specific shoulder orthopedic pathologies (e.g. superior labral tear from anterior to posterior (SLAP) lesions or full thickness rotator cuff tears), the PT decided not performing passive or orthopedic special tests [32, 33]. For these reasons, according to the diagnostic triage proposed by Ristori et al .[34], diagnosis was non-specific SP on supposed peripheral nociceptive pain mechanism. At the end of the physiotherapy session, the patient was instructed to perform self-mobilization of the shoulder as home exercise twice a day for 3 days until the next physiotherapy treatment $[35,36]$.

After the physiotherapy session, the patient experienced relief of the symptoms until the same evening, $\mathrm{NPRS}=5 / 10$ [37]. Then, the pain has reoccurred and increased, till forcing him to come back to the ED. The ED physician carried out another medical examination. Vital parameters at the time of admission were BP of $110 / 90 \mathrm{mmHg}, \mathrm{RR}$ of $16 \mathrm{rpm}, \mathrm{HR}$ of $98 \mathrm{bpm}$ and pulse oximetry saturation level of $100 \%$. Any other type of clinical assessment was unremarkable. The conclusive diagnosis was right MSK shoulder syndrome, and the ED physician performed an intramuscular injection of thiocolchicoside $4 \mathrm{mg} / 2 \mathrm{ml}$ and diclofenac $75 \mathrm{mg} / 3 \mathrm{ml}$ for pain-relieving. Upon discharge, the patient was instructed performing a daily intramuscular injection with the same dosages and drugs.

\section{Differential diagnosis}

The morning of the day after, the patient returned to the outpatient physiotherapy's clinic arguing that pain had shifted from the right shoulder to the left (Fig. 2). New symptom was sharp pain on the left shoulder, described as constant and oppressive (NPRS $=9 / 10)$, radiating down the upper limb and the pectoral region, while the right SP was currently improved at NPRS $=4$ / 10. The patient also reported systemic symptoms as dyspnea, fatigue, shortness of breath and diaphoresis, while palpation of the painful regions did not reproduce his own symptoms $[15,22,38]$. Examinations of cervical and thoracic spine, as well as costochondral joints were found normal [39]. Therefore, the PT correlated the current new symptoms to an underlying cardiovascular referred pain $[40,41]$. In order to properly screen possible red flags, the OSPRO-ROS 23-item review-ofsystems screening tool [42-45] was administered with positive response, proving the need of a more focused review-of-systems. Vitals were evaluated using automatic monitoring devices as blood pressure machine, SFIGMO DIGITALE AUTOMATICO-SMART (mod.32921, GIMA S.p.A, 20060, Gessate (Milan),Italy), and index finger oximeter, OXY-3 (mod.35090, GIMA S.p.A, GIMA S.p.A, 20060, Gessate (Milan),Italy), reporting BP of $135 / 90 \mathrm{mmHg}$, HR of $95 \mathrm{bpm}$, pulse oxygen saturation level of $97 \%$, and RR of $25 \mathrm{rpm}$. Furthermore, the PT decided to refer him to his general practitioner, which after having performed a detailed review-of-systems and cardiopulmonary auscultation sent the patient to the ED with a suspected AMI. 

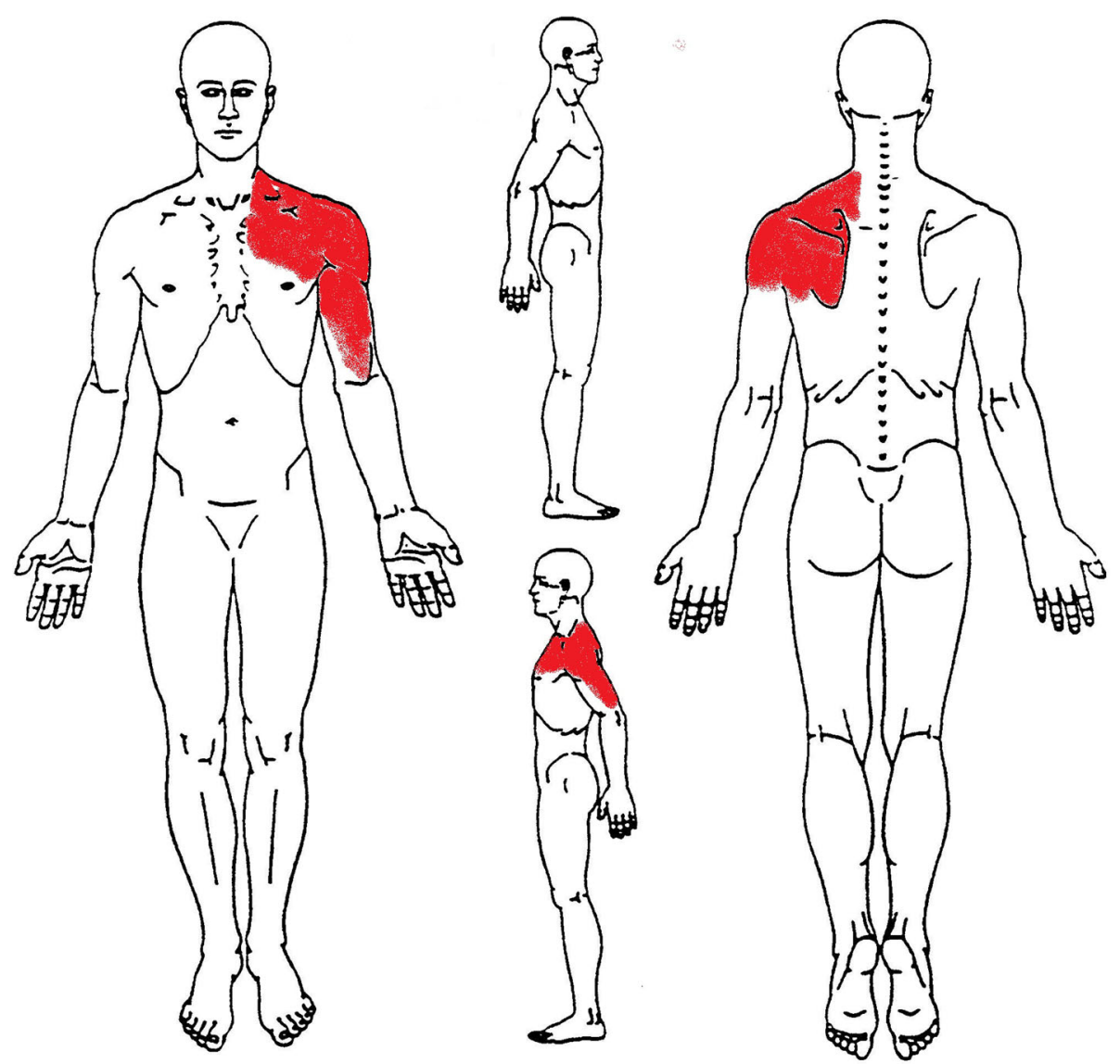

Fig. 2 Body chart. Symptoms at 2nd PT visit. In red NPRS 9/10 at rest

On admission at the ED, the patient underwent a third medical assessment. His vitals were $\mathrm{BP}$ of $130 / 90 \mathrm{mmHg}$, HR of $98 \mathrm{bpm}$, RR of $25 \mathrm{rpm}$, pulse oximetry saturation level of $97 \%$. Neurologic and pulmonary systems were normal and abdominal palpation revealed minimal tenderness in the epigastric region.

During the cardiologic visit 12-lead electrocardiography (ECG) and routine blood test were performed. The ECG showed elevation of the ST-segment and low voltage of the QRS complex (Fig. 3).

High level of cardiac troponin $4.9 \mathrm{mg} / \mathrm{dL}$ was detected. Afterwards bedside echocardiogram and color Doppler showed anterolateral septal-apical necrosis, severe left ventricular disfunction and light pulmonary arterial hypertension. Lastly, coronary angiography demonstrated a complete occlusion of proximal portion of left anterior descending artery (LAD) (Fig. 4). The patient was admitted to the intensive cardiologic care unit with a diagnosis of acute ST-elevation myocardial infarction due to occlusive coronary artery disease. Percutaneous transluminal coronary angioplasty (PTCA) was performed and a drug-eluting stent (DES) on LAD was planted in the cath lab immediately after.

\section{Outcomes}

After a week of hospitalization in the surgical unit, the heart surgeon decided to subject the patient to the implantation of an implantable cardioverter defibrillator (ICD) due to persistent arrhythmia. At 3 months followup, ICD has been evaluated and no signs of intervention were detected. Furthermore, neither signs nor symptoms of SP or viscerogenic disease has been reported. Thereafter, the cardiologist allowed performing a cardiological physiotherapy program, which has been carried out for 4 weeks after the cardiologist prescription in a licensed outpatient clinic for cardiological rehabilitation. The exercise protocol used was similar to the recently published exercise protocol for cardiac rehabilitation of Satyamurthy et al., 202 0[46]. The outcome measures adopted for the evaluation of the patient's achievements were the 6 min walking test for the endurance performance [47], the Borg scale for self-perceived exertion [48], and the Medical Outcome Study 36-item Short-Form Health Survey [49] to assess the awareness and the quality of life. Finally, at 6 months follow-up, the cardiologist authorized the patient to a complete return to work after reporting a 31/40 value on general perceived self-efficacy 


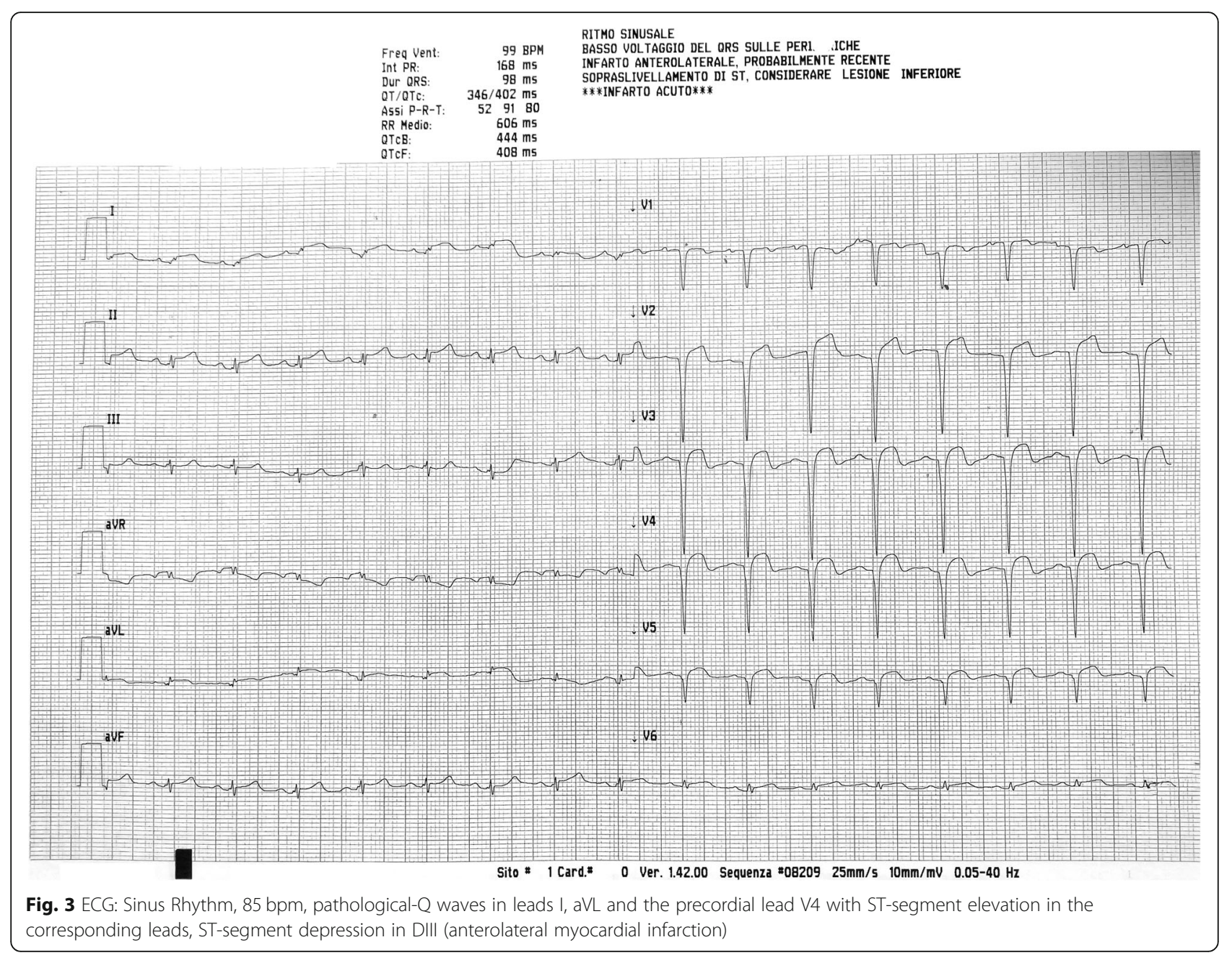

scale (GSE )[50]. For a more detailed story management, see the timeline in Fig. 5.

\section{Discussion and conclusion}

Our case report describes the clinical decision making by a PT that led to detect a non-MSK condition in a 46y-old male with SP symptoms. SP is one of the most frequent musculoskeletal diseases in outpatient clinics and its prevalence in the general population is within $27 \%$ in the lifetime $[2,5,6]$. Moreover, as in our case, shoulder pain can be a somatic sign of certain visceral lifethreatening pathologies which mimic musculoskeletal disorders of the trunk or the upper limbs [39-41, 51]. Among these, it must be considered AMI [51], which usually refers pain to chest or upper limb $[9,38,40,41]$. For that reason, physicians and healthcare professionals must be alert in differential diagnosis process during the physical examination of the shoulder [5, 23, 40, 41], especially when palpation of the painful areas does not reproduce the patient symptoms [52], or in presence of autonomic signs as fever, diaphoresis, nausea and respiratory complaints which frequently occurring in presence of heart related visceral pain [7, 53, 54]. Those signs, within musculoskeletal context are defined as Red Flags (RF) (e.g. clinical indicators of possible serious pathologies )[40, 41] and, notwithstanding RFs as selfcontained screening tools seem to be weak during the physical examination of the patients with some MSK diseases [52], the combination of multiple RFs for the screening for referral process is promising $[55,56]$. Furthermore, clinical decision making in patients with MSK pain conditions can be supported using validated tools [42-45], in order to perform or not a review-of-systems $[5,23]$ and for medical referral [42-45]. As in this case, direct access to PTs is becoming an increasingly common practice [9], however, not all PT in the world are allowed to prescribe imaging [57], hence, it is critical that PT being able to perform a clinical review-ofsystems within differential diagnosis process [40, 41]. For this reason, screening of personal and family medical history, assessment of the risk factors (e.g. smoking, body mass index, congenital or hereditary diseases), 


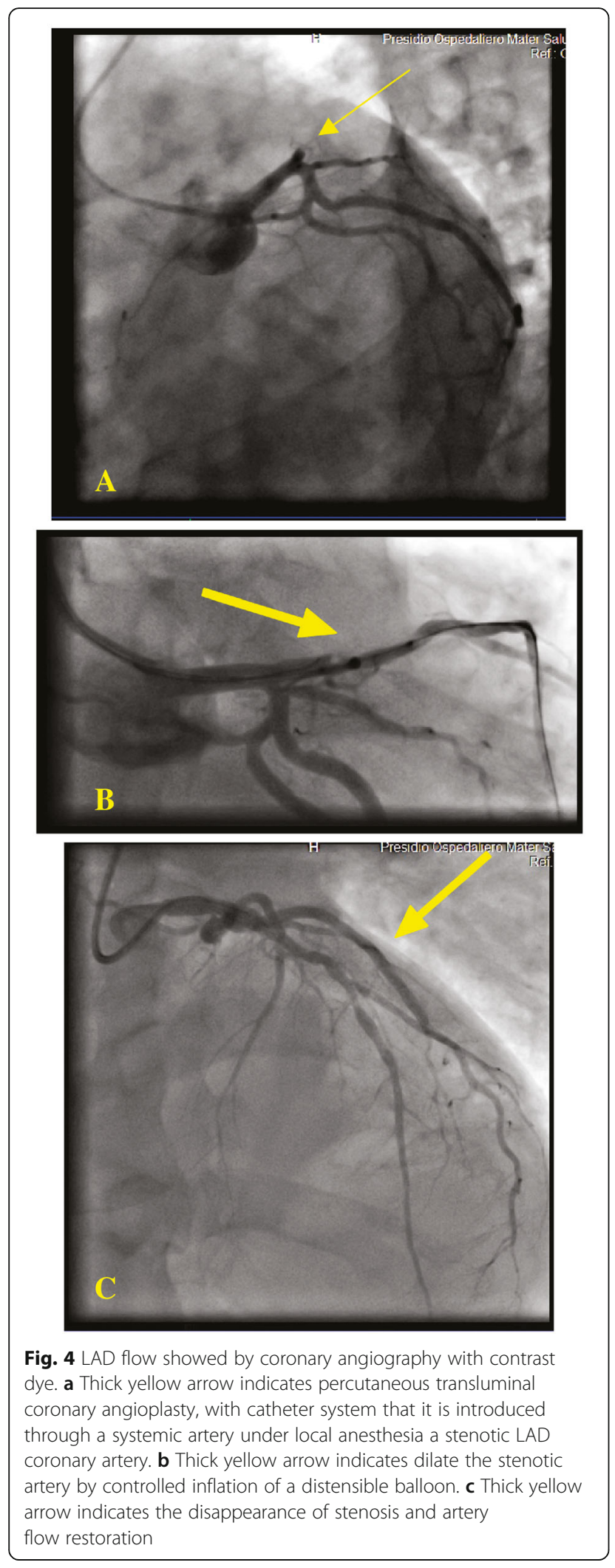

screening for RFs [55], watchful waiting [52], and linking RFs symptomology directly with health status and vital parameters, are mandatory professional skills for PT in direct access clinical settings [5, 9, 23], as it has been clearly stated from a widespread clinical practice guideline [58]. From the patient perspective, the physical examination conducted by the PT demonstrated the professional skills needed to decision-making process for differential diagnosis and medical referral. About medication intake in case of suspected cardiovascular diseases, the use of non-steroidal anti-inflammatory drugs (NSAID) as potential aggravating factors in case of AMI are well known [59-63]. Specifically, diclofenac-based medications should be carefully administered under medical prescription and thus avoided as over-thecounter drugs because of high cardiovascular associated risks [60]. Moreover, attention must be paid even to use other NSAID such as ibuprofen or paracetamol, which despite have shown lower risks of cardiovascular events than diclofenac [59-61], pose a substantial aggravating risk in case of AMI. Conversely, acetylsalicylic acid drugs shall be mentioned in this context because their use under suspicion of AMI must be encouraged in preventing major cardiovascular diseases $[64,65]$. The shift in symptom from the right to the left shoulder is an unusual presentation of AMI within clinical scenario, however the array of symptoms that could be referred by patients after an AMI is multiple [8]. Among them, pain in one or both shoulders seem to be correlated to the site of AMI [66]. The network underlying this phenomenon is related to viscerosomatic convergence onto upper thoracic spinothalamic tract neurons. In fact, both cardiac sensory information and somatic sensory information from the chest and upper limb merge onto the same bunch of spinothalamic tract neurons in the upper thoracic (T1-T5) spinal dorsal horn segments [67]. Consequently, this convergence does not allow to project the incoming information accurately onto the somatosensory cortex [68]. This mechanism leads to overlapped pathways for somatic sensations, and besides it has been further tested in a recent case report in which a 29 male patient referred intermittent crushing substernal chest pain localized to the left lateral sternal border which radiated to the left arm following vagal nerve stimulation [69]. Moreover, as for what the neurophysiology is concerned, tissue trauma may result in an afferent barrier of nociceptive transmission that could alter the threshold for excitation stimuli in both central and peripheral areas, enhancing the afferent transmissions to the dorsal horn of the spinal cord, thus expanding the receptive field of dorsal horn neurons, which is called central hypersensitization [70, 71]. The patient in the present case report has started to feel shoulder symptoms on the right side, which had been referred to 


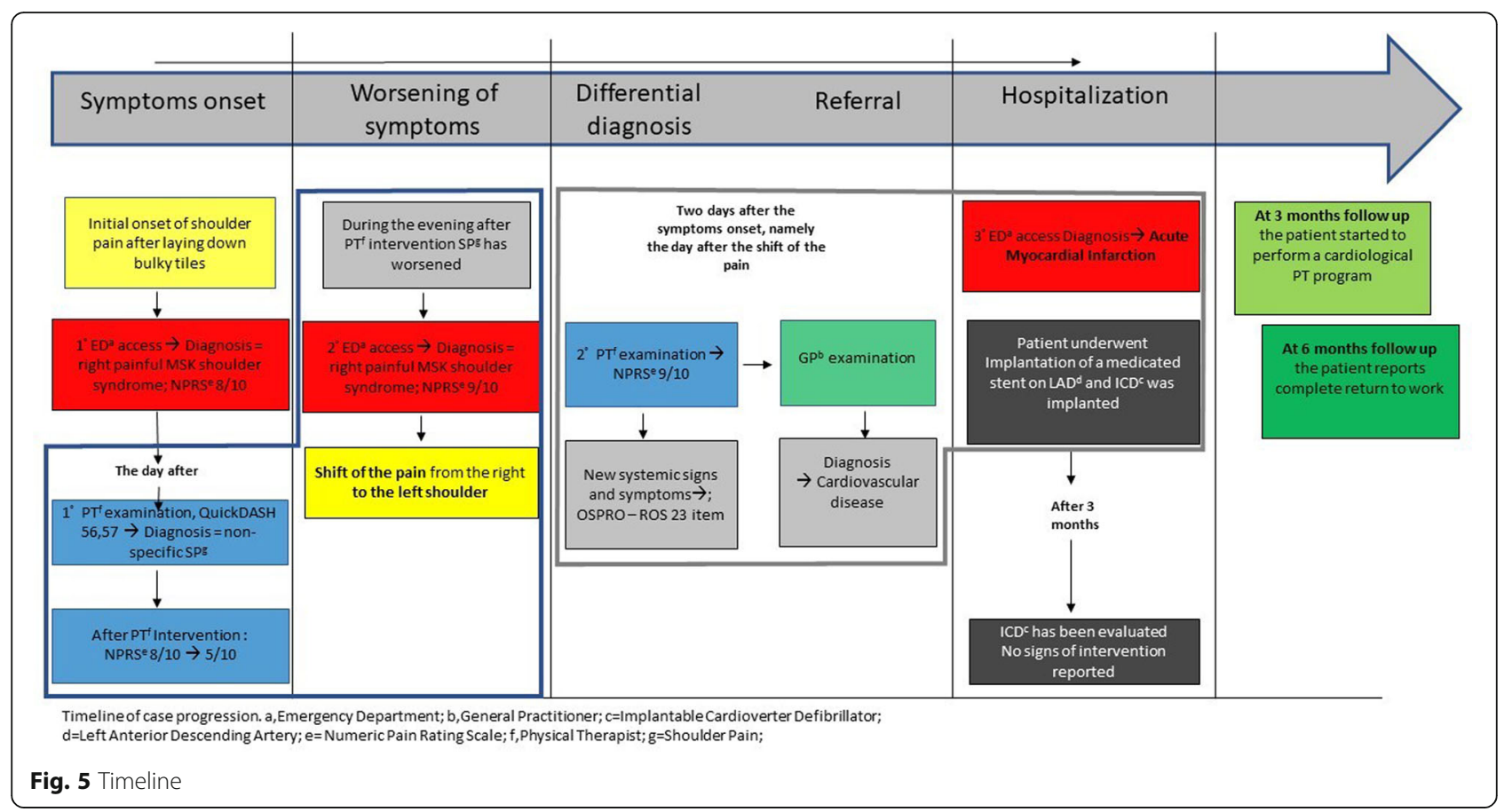

as the site of several dislocations in childhood. Conversely, the pain in the left shoulder and the pectoral region showed up only 9 days after the initial symptom onset. Furthermore, the left shoulder pain has started concurrently with the autonomic symptoms as dyspnea, fatigue, shortness of breath and diaphoresis which has been recently linked to specific sites of myocardial infarction [72]. In this perspective, the progression of the hypoxic injuries induced in the myocardium following an inadequate exposure to oxygen supply could have affected specific sympathetic fibers, that even provoked the shift in somatic pain as well. However, as matters stand at present, there is not sufficient evidence to enable us to state which of the above mechanisms is actually responsible for the development of the shift in symptom from the right to the left shoulder.

To the best of the authors' knowledge, this is the first documented case of AMI that has been manifested through an upper limb MSK pain pattern recognized by a PT. Such an unusual clinical presentation, with a sudden shift from right to the left side with new signs and symptoms, allowed the detection of cardiovascular disease during physical examination. This case report highlights the importance of the clinical reasoning during differential diagnosis process by healthcare professional within musculoskeletal context.

\section{Abbreviations}

AMl: Acute Myocardial Infarction; BP: Blood Pressure;

ECG: Electrocardiography; ED: Emergency Department; GSE: General perceived self-efficacy scale; HR: Heart Rate; ICD: Implantable Cardioverter Defibrillator; LAD: Left anterior Descending Artery; MRC: Medical Research
Council scale; MSK: Musculoskeletal; NPRS: Numeric Pain Rating Scale; PT: Physiotherapist; RF: Red Flag; ROM: Range of Motion; RR: Respiratory Rate; SLAP: Superior Labral Tear from Anterior to Posterior; SP: Shoulder Pain; NSAI

D: Non-Steroidal Anti-Inflammatory Drugs

\section{Acknowledgments}

The authors of the present manuscript are grateful to Dr. Giacomo Rossettini PT PhD, Department of Neuroscience, Rehabilitation, Ophthalmology, Genetics, Maternal and Child Health, University of Genova - Campus of Savona, Savona, Italy, for his invaluable contribution in relation to the critical revision of the manuscript for important intellectual content.

\section{Authors' contributions}

LS completed all examinations. LS and FM decided about final referral. LS, $V B, F B, F M$ and $M T$ drafted the manuscript. LS performed first clinical examination and VB and FM provided consultation about interpretation of clinical findings of examination, diagnosis and imaging method suggested. FB, MT and FM performed clinical revision of paper's content. The authors read and approved the final manuscript.

\section{Funding}

No financial or material support of any kind was received for the work described in this article.

\section{Availability of data and materials}

All data generated or analyzed during this care report are included in this published study. Other information of this case report are available from the corresponding author on reasonable request.

Ethics approval and consent to participate

Not applicable.

\section{Consent for publication}

Written informed consent was obtained from the patient for publication of this Case report and any accompanying images. A copy of the written consent is available for review by the Editor of this journal.

Competing interests

The authors declare that they have no competing interests. 


\section{Author details}

'Department of Neurosciences, Rehabilitation, Ophthalmology, Genetic and Maternal Infantile Sciences (DINOGMI), University of Genova - Campus of Savona, Savona, Italy. ${ }^{2}$ Department of Medicine and Health Science "Vincenzo Tiberio", University of Molise c/o Cardarelli Hospital, C/da Tappino, Campobasso, Italy.

\section{Received: 26 November 2020 Accepted: 19 January 2021}

\section{Published online: 15 February 2021}

\section{References}

1. Luime JJ, Koes BW, Hendriksen IJM, Burdorf A, Verhagen AP, Miedema HS, Verhaar JAN. Prevalence and incidence of shoulder pain in the general population; a systematic review. Scand J Rheumatol. 2004;33:73-81.

2. Greving K, Dorrestijn O, Winters JC, Groenhof F, van der Meer K, Stevens M, Diercks RL. Incidence, prevalence, and consultation rates of shoulder complaints in general practice. Scand J Rheumatol. 2012;41:150-5.

3. Lawrence RL, Braman JP, Laprade RF, Ludewig PM. Comparison of 3dimensional shoulder complex kinematics in individuals with and without shoulder pain, part 1: Sternoclavicular, acromioclavicular, and scapulothoracic joints. J Orthop Sports Phys Ther. 2014;44:636-45.

4. Rekola KE, Keinanen-Kiukaanniemi S, Takala J. Use of primary health services in sparsely populated country districts by patients with musculoskeletal symptoms: consultations with a physician. J Epidemiol Community Health. 1993;47:153-7

5. Mitchell C, Adebajo A, Hay E, Carr A. Shoulder pain: diagnosis and management in primary care. Br Med J. 2005;331:1124-8.

6. Malavolta EA, Gracitelli MEC, Assunção JH, de MR PG, AZF d S, AAF N. Shoulder disorders in an outpatient clinic: an epidemiological study. Acta Ortop Brasil. 2017:25:78-80.

7. Sikandar S, Dickenson AH. Visceral pain: the ins and outs, the ups and downs. Curr Opin Support Palliat Care. 2012;6:17-26.

8. Berg J, Björck L, Dudas K, Lappas G, Rosengren A. Symptoms of a first acute myocardial infarction in women and men. Gender Medicine. 2009;6:454-62.

9. Weber MD. Screening and evaluation of the cardiovascular and pulmonary systems in patients presenting with upper extremity impairments. J Hand Ther. 2010:23:127-39.

10. Mohseni J, Kazemi T, Maleki M, Beydokhti H. A systematic review on the prevalence of acute myocardial infarction in Iran. Heart Views. 2017:18:125.

11. Bradley SM, Borgerding JA, Wood GB, Maynard C, Fihn SD. Incidence, risk factors, and outcomes associated with in-hospital acute myocardial infarction. JAMA Netw Open. 2019;2:e187348.

12. Čulić V, Eterović D, Mirić D, Silić N. Symptom presentation of acute myocardial infarction: influence of sex, age, and risk factors. Am Heart J. 2002; 144:1012-7.

13. Bruyninckx R, Aertgeerts B, Bruyninckx P, Buntinx F. Signs and symptoms in diagnosing acute myocardial infarction and acute coronary syndrome: a diagnostic meta-analysis. Br J Gen Pract. 2008:58:105-11.

14. Krolak K. Claims case study: missed myocardial infarctions: Cire; 2018. https://curi.com/news/missed-mi/. Accessed 18 Nov 2020

15. Primary Care for the Physical Therapist - 3rd Edition. https://www.elsevier. com/books/primary-care-for-the-physical-therapist/boissonnault/9780-323-63897-5. Accessed 18 Nov 2020.

16. Cook CE, Décary S. Higher order thinking about differential diagnosis. Braz J Phys Ther. 2020;24:1-7.

17. VanWye WR, Pinerola J, Ogle KC, Wallmann HW. Screening for referral by a sports physical therapist reveals an effort thrombosis in a collegiate pitcher: a CASE report. Int J Sports Phys Ther. 2016;11:607-13.

18. Slaven EJ, Mathers J. Differential diagnosis of shoulder and cervical pain: a case report. J Man Manipulative Ther. 2010;18:191-6.

19. Mathers JJ. Differential diagnosis of a patient referred to physical therapy with neck pain: a case study of a patient with an atypical presentation of angina. J Man Manipulative Ther. 2012;20:214-8.

20. Perry M. Differential diagnosis: musculoskeletal pain vs. cardiogenic pain Research innovation scholarship entrepreneurship 18-11-2020; 2012.

21. Mintken PE, Glynn P, Cleland JA. Psychometric properties of the shortened disabilities of the arm, shoulder, and hand questionnaire (QuickDASH) and numeric pain rating scale in patients with shoulder pain. J Shoulder Elb Surg. 2009;18:920-6.

22. Gräni $C$, Senn O, Bischof M, Cippà PE, Hauffe T, Zimmerli L, Battegay E, Franzen D. Diagnostic performance of reproducible chest wall tenderness to rule out acute coronary syndrome in acute chest pain: a prospective diagnostic study. BMJ Open. 2015;5:e007442

23. House J, Mooradian A. Evaluation and management of shoulder pain in primary care clinics. South Med J. 2010;103:1129-35.

24. Petersen CM, Hayes KW. Consruct validity of Cyriax's selective tension examination: association of end-feels with pain at the knee and shoulder. J Orthop Sports Phys Ther. 2000;30:512-27.

25. Orthopedic Physical Assessment - 5th Edition. https://www.elsevier.com/ books/orthopedic-physical-assessment/magee/978-0-7216-0571-5. Accessed 30 Oct 2020.

26. Paternostro-Sluga T, Grim-Stieger M, Posch M, Schuhfried O, Vacariu G, Mittermaier C, Bittner C, Fialka-Moser V. Reliability and validity of the Medical Research Council (MRC) scale and a modified scale for testing muscle strength in patients with radial palsy. J Rehabil Med. 2008;40:665-71.

27. Jull G, Bogduk N, Marsland A. The accuracy of manual diagnosis for cervial zygapophysial joint pain syndromes. Med J Aust. 1988;148:233-6.

28. Cooper G, Bailey B, Bogduk N. Cervical zygapophysial joint pain maps. Pain Med. 2007:8:344-53.

29. Siegenthaler A, Eichenberger U, Schmidlin K, Arendt-Nielsen L, Curatolo M. What does local tenderness say about the origin of pain? An investigation of cervical zygapophysial joint pain. Anesth Analg. 2010;110:923-7.

30. Vanti C, Conteddu L, Guccione A, Morsillo F, Parazza S, Viti C, Pillastrini P. The upper limb Neurodynamic test 1: intra- and Intertester reliability and the effect of several repetitions on pain and resistance. J Manip Physiol Ther. 2010;33:292-9.

31. Coppieters M, Stappaerts K, Janssens K, Jull G. Reliability of detecting "onset of pain" and "submaximal pain" during neural provocation testing of the upper quadrant. Physiother Res Int. 2002;7:146-56.

32. Lewis JS. Rotator cuff tendinopathy/subacromial impingement syndrome: is it time for a new method of assessment? Br J Sports Med. 2009:43:259-64.

33. Hegedus EJ, Goode A, Campbell S, Morin A, Tamaddoni M, Moorman CT, Cook C. Physical examination tests of the shoulder: a systematic review with meta-analysis of individual tests. Br J Sports Med. 2008:42:80-92.

34. Ristori D, Miele S, Rossettini G, Monaldi E, Arceri D, Testa M. Towards an integrated clinical framework for patient with shoulder pain. Arch Physiother. 2018. https://doi.org/10.1186/s40945-018-0050-3.

35. Ribeiro DC, Sole G, Venkat R, Shemmell J. Differences between clinicianand self-administered shoulder sustained mobilization on scapular and shoulder muscle activity during shoulder abduction: a repeated-measures study on asymptomatic individuals. Musculoskelet Sci Pract. 2017;30:25-33.

36. Vicenzino B, Paungmali A, Teys P. Mulligan's mobilization-with-movement, positional faults and pain relief: current concepts from a critical review of literature. Man Ther. 2007;12:98-108.

37. Michener LA, Snyder AR, Leggin BG. Responsiveness of the numeric pain rating scale in patients with shoulder pain and the effect of surgical status. J Sport Rehabil. 2011;20:115-28.

38. Albarran J, Durham B, Gowers J, Dwight J, Chappell G. Is the radiation of chest pain a useful indicator of myocardial infarction? A prospective study of 541 patients. Accid Emerg Nurs. 2002;10:2-9.

39. Amsterdam EA, Wenger NK, Brindis RG, et al. 2014 AHAVACC guideline for the management of patients with non-st-elevation acute coronary syndromes: a report of the American college of cardiology/American heart association task force on practice guidelines. Circulation. 2014;130:e344-426.

40. Goodman CC. Screening for medical problems in patients with upper extremity signs and symptoms. J Hand Ther. 2010;23:105-26.

41. Differential Diagnosis for Physical Therapists - 6th Edition. https://www. elsevier.com/books/differential-diagnosis-for-physical-therapists/heick/9780-323-47849-6. Accessed 30 Oct 2020.

42. George SZ, Beneciuk JM, Lentz TA, Wu SS. The optimal screening for prediction of referral and outcome (OSPRO) in patients with musculoskeletal pain conditions: a longitudinal validation cohort from the USA. BMJ Open. 2017. https://doi.org/10.1136/bmjopen-2016-015188.

43. Beneciuk JM, Lentz TA, He Y, Wu SS, George SZ. Prediction of persistent musculoskeletal pain at 12 months: a secondary analysis of the optimal screening for prediction of referral and outcome (OSPRO) validation cohort study. Phys Ther. 2018;98:290-301.

44. George SZ, Beneciuk JM, Lentz TA, Wu SS, Dai Y, Bialosky JE, Zeppieri G. Optimal screening for prediction of referral and outcome (OSPRO) for musculoskeletal pain conditions: results from the validation cohort. J Orthop Sports Phys Ther. 2018;48:460-75.

45. George SZ, Beneciuk JM, Bialosky JE, Lentz TA, Zeppieri G, Pei Q, Wu SS. Development of a review-of-systems screening tool for orthopaedic 
physical therapists: results from the optimal screening for prediction of referral and outcome (OSPRO) cohort. J Orthop Sports Phys Ther. 2015;45: $512-26$

46. Satyamurthy A, Prabhu N, Padmakumar R, Babu AS. Feasibility of an exercise-based cardiac rehabilitation algorithm in patients following percutaneous coronary intervention for acute coronary syndrome. Indian Heart J. 2020;72:289-92.

47. Bellet RN, Adams L, Morris NR. The 6-minute walk test in outpatient cardiac rehabilitation: validity, reliability and responsiveness-a systematic review. Physiotherapy (United Kingdom). 2012;98:277-86.

48. Aamot IL, Forbord SH, Karlsen T, Støylen A. Does rating of perceived exertion result in target exercise intensity during interval training in cardiac rehabilitation? A study of the Borg scale versus a heart rate monitor. J Sci Med Sport. 2014;17:541-5.

49. Kweon S, Sohn MK, Jeong JO, Kim S, Jeon H, Lee H, Ahn SC, Park SH, Jee S. Quality of life and awareness of cardiac rehabilitation program in people with cardiovascular diseases. Ann Rehabil Med. 2017:41:248-56.

50. Zotti AM, Balestroni G, Cerutti P, Ferrario SR, Angelino E, Miglioretti M. Application of the general perceived self-efficacy scale in cardiovascular rehabilitation. Monaldi Arch Chest Dis. 2016. https://doi.org/10.4081/ monaldi.2007.451.

51. Thygesen K, Alpert JS, Jaffe AS, et al. Third universal definition of myocardial infarction. Eur Heart J. 2012:33:2551-67.

52. Cook CE, George SZ, Reiman MP. Red flag screening for low back pain: nothing to see here, move along: a narrative review. Br I Sports Med. 2018; 52:493-6.

53. Body R, Carley S, Wibberley C, McDowell G, Ferguson J, Mackway-Jones K. The value of symptoms and signs in the emergent diagnosis of acute coronary syndromes. Resuscitation. 2010;81:281-6.

54. Maselli F, Palladino M, Barbari V, Storari L, Rossettini G, Testa M. The diagnostic value of red flags in thoracolumbar pain: a systematic review. Disabil Rehabil. 2020. https://doi.org/10.1080/09638288.2020.1804626.

55. Finucane LM, Downie A, Mercer C, Greenhalgh SM, Boissonnault WG, PoolGoudzwaard AL, Beneciuk JM, Leech RL, Selfe J. International framework for red flags for potential serious spinal pathologies. J Orthop Sports Phys Ther. 2020;50:350-72

56. Roffi M, Patrono C, Collet JP, et al. 2015 ESC guidelines for the management of acute coronary syndromes in patients presenting without persistent STsegment elevation: task force for the management of acute coronary syndromes in patients presenting without persistent ST-segment elevation of the european society of cardiology (ESC). Eur Heart J. 2016;37:267-315.

57. Boyles RE, Gorman I, Pinto D, Ross MD. Physical therapist practice and the role of diagnostic imaging. J Orthop Sports Phys Ther. 2011;41:829-37.

58. Clinical practice guidelines for the management of rotator cuff syndrome in the workplace Clinical Practice Guidelines. https://www.guidelinecentral. $\mathrm{com} /$ summaries/clinical-practice-guidelines-for-the-management-of-rotatorcuff-syndrome-in-the-workplace/\#section-society. Accessed 5 Nov 2020.

59. Baigent C, Bhala N, Emberson J, et al. Vascular and upper gastrointestinal effects of non-steroidal anti-inflammatory drugs: meta-analyses of individual participant data from randomised trials. Lancet. 2013;382:769-79.

60. Schmidt M, Sørensen HT, Pedersen L. Diclofenac use and cardiovascular risks: series of nationwide cohort studies. BMJ (Online). 2018. https://doi.org/ 10.1136/bmi.k3426

61. Schmidt M, Lamberts M, Olsen AMS, et al. Cardiovascular safety of nonaspirin non-steroidal anti-inflammatory drugs: review and position paper by the working group for cardiovascular pharmacotherapy of the European Society of Cardiology. Eur Heart J. 2016;37:1015-23.

62. Bally M, Dendukuri N, Rich B, Nadeau L, Helin-Salmivaara A, Garbe E, Brophy JM. Risk of acute myocardial infarction with NSAIDs in real world use: Bayesian meta-analysis of individual patient data. BMJ (Online). 2017;357:1909.

63. Masclee GMC, Straatman H, Arfè A, et al. Risk of acute myocardial infarction during use of individual NSAIDs: a nested case-control study from the SOS project. PLoS One. 2018;13:e0204746.

64. Ittaman S V, JJ WW, Rezkalla SH. The role of aspirin in the prevention of cardiovascular disease. Clin Med Res. 2014;12:147-54.

65. Gelbenegger G, Postula M, Pecen L, Halvorsen S, Lesiak M, Schoergenhofer C, Jilma B, Hengstenberg C, Siller-Matula JM. Aspirin for primary prevention of cardiovascular disease: a meta-analysis with a particular focus on subgroups. BMC Med. 2019. https://doi.org/10.1186/s12916-019-1428-0.

66. Culic V, Miric D, Eterovic D. Correlation between symptomatology and site of acute myocardial infarction. Int J Cardiol. 2001;77:163-8.
67. Foreman RD, Garrett KM, Blair RW. Mechanisms of cardiac pain. Compr Physiol. 2015;5:929-60.

68. Leach A, Fisher M. Myocardial ischaemia and cardiac pain - a mysterious relationship. Br J Pain. 2013;7:23-30

69. Nichols JB, McCallum AP, Khattar NK, Wei GZ, Gopinathannair R, Nauta HJW, Neimat JS. Pseudoanginal chest pain associated with vagal nerve stimulation: a case report. BMC Neurol. 2020. https://doi.org/10.1186/s12883020-01693-5.

70. McDowell TS. Peripheral mechanisms of pain transmission and modulation. Pain: Springer International Publishing; 2019. p. 37-40.

71. Yam MF, Loh YC, Tan CS, Adam SK, Manan NA, Basir R. General pathways of pain sensation and the major neurotransmitters involved in pain regulation. Int J Mol Sci. 2018. https://doi.org/10.3390/ijms19082164.

72. Rahman MN, Artani A, Baloch F, Hussain B. Severity of chest pain among acute myocardial infarction patients with diagonal branch vessel disease: a pilot study. Cureus. 2019. https://doi.org/10.7759/cureus.5519.

\section{Publisher's Note}

Springer Nature remains neutral with regard to jurisdictional claims in published maps and institutional affiliations.
Ready to submit your research? Choose BMC and benefit from:

- fast, convenient online submission

- thorough peer review by experienced researchers in your field

- rapid publication on acceptance

- support for research data, including large and complex data types

- gold Open Access which fosters wider collaboration and increased citations

- maximum visibility for your research: over $100 \mathrm{M}$ website views per year

At $\mathrm{BMC}$, research is always in progress.

Learn more biomedcentral.com/submissions 